\title{
Una Obra Mexicana del Siglo XVII (1601), Desconocida
}

$F^{N}$ el sigiloso escrutinio que el cura, el barbero, la sobrina y el ama hicieron en la librería del ingenioso hidalgo Don Quijote, condenaron a la hoguera numerosos libros de caballería siguiendo el imperativo mandato de la sobrina, que dijo:

"No, no hay que perdonar a ninguno, porque todos han sido los dañadores: mejor será arrojarlos por las ventanas al patio, y hacer un rimero dellos y pegarles fuego, y si no, llevarlos al corral, y allí se hará la hoguera, y no se ofenderá el humo." 1

Fué así como merecieron el castigo del fuego: Amadis de Gaula, Las sergas de Esplandián, Amadís de Grecia, Don Olivante de Laura, Florismarte de Hircania, El caballero Platir, Espejo de caballerias, Palmerin de Oliva, Palmerin de Inglaterra, Don Belianis, Los diez libros de fortuna de amor, Antonio de Lofrasso, El pastor de Iberia, Ninfas de Henares y Desengaños de amor, y otras más que echaron al corral para prender y engrosar la pira, que el ama atizó con cuantos libros pudo encontrar en el corral y en toda la casa. ${ }^{2}$

E1 pasaje da la oportunidad a Cervantes para menospreciar y condenar por malos los libros de caballería, echándolos al fuego inmisericorde. Condenación que se externa en toda su obra, paradójicamente; puesto que Don Quijote es el mejor libro de caballería -entre otras muchas cosas-, como es bien sabido.

Irremisiblemente quema Cervantes El pastor de Iberia, de Bernardo de la Vega, "envidioso, descuidado y tardo", " por considerarlo como decía el ama, "dañador".

Era éste, gentil hombre, nacido en Madrid probablemente, y muerto después de 1623; al decir de Juan Antonio de Ibarra; ${ }^{4}$ más 
tarde canónigo de Tucumán. ${ }^{5}$ La obra es una novela pastoril en prosa y verso, en cuatro libros. ${ }^{6}$

Pero si el autor ha pasado a la posteridad precisamente por la condenación hecha por Cervantes, más nos interesa por ser el autor de una obra desconocida en su totalidad: La bella Cotalda y cerco de París.

Es por Antonio de León Pinelo, por quien sabemos que Bernardo de la Vega es el autor de La bella Cotalda y cerco de París. Relación de las grandezas del Perú, México i los Angeles, impresa en México en $1601 ;^{7}$ y por Nicolás Antonio por quien se sabe fué impresa en casa de Melchor Ocharte, ${ }^{8}$ uno de los primeros impresores mexicanos.

Ninguno de nuestros bibliógrafos posteriores, ni aun José Toribio Medina, víeron el libro. Unos lo pasan por alto, José Mariano Beristáin de Souza, Joaquín García Icazbalceta. ${ }^{9}$ Vicente P. Andrade dice no conocerla; ${ }^{10}$ otros, en cambio, como el propio Medina y Antonio Palau y Dulcet ${ }^{11}$ siguen a Nicolás Antonio en la obra citada.

El distinguido historiador y bibliógrafo chileno, al hablar de Melchor Ocharte (1599-1601), nieto de Juan Pablos por la vía materna - María Figueroa, era el nombre de su madre- y de Pedro Ocharte (1563-1592), dice que trabajó en Tlaltelolco imprimiendo el Confesionario de fray Juan Bautista (1599) ; Primera parte de las advertencias a los confesores de Indias; tesis profesionales universitarias del Colegio de Santa Cruz y otros libros, entre ellos uno de: ra". 12

"Bernardo de la Vega, en 1601, que nadie ha visto hasta aho-

duda de la existencia de la obra de Bernardo de la Vega:

"Hay que considerar un anacronismo suponer la impresión en México de una obra escrita por el Canónigo de Córdoba del Tucumán. ¿Por qué habría de ocurrir a las presas de México cuando tenía más cerca las de Lima, y aun las de Epaña? En la tipografía mexicana no hay ejemplo de semejante hecho, pues lo más que llegó a ocurrir es que se imprimiese alguna relación u otra obrilla publicada primero en Lima o viceversa." 13

y agrega :

"Que en México por López Dávalos, aunque en 1604, se imprimió La grandeza mexicana de Bernardo de Balbuena, en cuyo 
libro se encuentra una carta del autor a doña Isabel de Tobar y Guzmán describiendo la famosa ciudad de México y sus grandezas.

"Ni en lo antiguo, ni en Eguiara, ni Beristain, ni García Icazbalceta, ni nadie ha visto el libro atribuido a Bernardo de la Vega. $\mathrm{Y}$ adviértase que en los viejos manuscritos redactados muchas veces con abreviaturas, no sería nada improbable que Bernardo de Valbuena como solía escribirse el apellido Balbuena; se hubiese trocado en la imprenta en Bernardo de Vega. Dos clérigos escribiendo mismo tema, en verso y en años próximos, es algo anómalo, no habiendo mediado certamen. Por inferencia debe llegarse a la conclusión de que no existe el impreso mexicano atribuído a Bernardo de la Vega." 13

No quiso darle fe a las noticias bibliográficas dadas por Pinelo y Nicolás Antonio, aun cuando toma Medina como fuentes a ambos y los transcribe en numerosísimas ocasiones en sus nutridas bibliografías. Con ello, al asentar por una parte el libro de La bella Cotalda y cerco de París, entre los que forman su catálogo y por otra dejar escrita la cita anterior, incurre en contradicción flagrante.

Residía ya en México Bernardo de la Vega, cuando fué aprehendido por el Santo Tribunal de la Inquisición, en casa de su amigo Diego de la Parra, requerido para contestar a ciertos cargos por haberse referido a una real cédula sobre el uso de negros por los oficiales del Santo Oficio. ${ }^{14}$

$Y$ no sólo eso, sino que en el mes de junio de 1600 pidió permiso al virrey para imprimir su libro, de acuerdo con to establecido en esas épocas. He aquí la licencia de impresión:

"Don Gaspar, etc. Por cuanto Bernardo de la Vega, Canónigo de la Catedral de Tucumán, en los reinos del Perú, me ha fecho relación que él ha compuesto un libro intitulado El Cerco de Paris por Enrico de Borbón, donde se trata de la estrecheza que la gente ciudadana padecía en él por la defensa de la fe y el favor y socorro fecho por el Rey Don Felipe Nuestro Señor, segundo de este nombre, en que hay cosas ejemplares y de valer, así en los tratos y orden de guerra como en los de urbanidad; y que para que se pudiese commicar a todos pretendía imprimirlo, pidiéndome le mandase dar licencia para ello; y por mí visto y que habiendo sometido el examen a personas doctas y de saitisfacción, y al doctor Dionisio de Rivera Flores, Canónigo de la Catedral de esta ciudad de México, se declaró ser lectura agradable, provechosa y muy conforme a la honestidad pública e ingenios levantados, y que así se le podía conceder la dicha licencia; 
por la presente le doy al dicho canónigo Bernardo de la Vega, para que haga imprimir a cualquier impresor que quisiere, el dicho. libro, e impreso, se traiga ante mí para que se tase el precio por que se ha de vender cada volumen; y mando que otra ninguna persona fuera de la que señalare y quisiese el susodicho, no imprima el dicho libro, so pena de perder los moldes y lo que imprimiere. Fecho en México, a tres dias del mes de Junio de mil seiscientos años. Entiéndase no haber de usar esta impresión por más tiempo de diez años. E1 conde de Monterrey, por mandado del Virrey, Pedro de Campos." 15

Un mes después, el 28 de julio de 1600 , se vió por el Cabildo de la ciudad una petición de De la Vega, para que le cubriesen los gastos de la impresión de su libro, que según su decir le costaba más de "dos mil y trescientos pesos ..." A lo cual el Cabildo contestó :

"E visto por la ciudad dijo: que attento que le consta quel libro quel canónigo bernardo de bega tiene compuesto y ymprimir con licencia del señor visorrey, trata de las grandezas desta ciudad, ctya memoria ymporta quede siempre biba y no se oscurezca con los largos tiempos, lo qual siempre pretenden las repúblicas bien ordenadas que desean que sus principios y grandezas permanezcan lo qual siempre procuran, y lo mismo los príncipes y aún tienen por buena suerte hallar escriptores y poetas que lo saquen a luz, acuerda que al dicho bernardo de la bega autor del dicho libro, se le den para su impresión seiscientos pesos de oro común y para que los cobre se le de luego librança." 16

$\mathrm{El}$ once de septiembre de dicho año se volvió a tratar del asunto asignándosele dicha cantidad definitivamente, de los Propios y $\mathrm{Ar}$ bitrios de la ciudad de México. ${ }^{17}$

¿Cuándo se imprimió el libro de Bernardo de la Vega? Atribuyen los citados bibliógrafos la fecha de 1601, en las prensas de Melchor de Ocharte. Por una declaración final que el propio Bernardo de la Vega hace en otro libro suyo intitulado:

Ramillete/de Flores Divinas,/Vidas de Sanctos, y/otras obras Espirituales. / $\uparrow-/$ Compvuesto en verso, / por Bernardo de la Vega, Canónigo de la/Cathedral de Tucumán, en las Pro/uincias del Pirú, nacido en / (Adorno) Corte, (adorno) / (adorno) al Ilustrissimo, y Re/uerendissimo Señor Don F. Garcia de Men/doça y Canonigo Arçobispo de Mexico,/ y del Consejo de Su Magestad. / (Adorno) Con Licencia./ (Líneas de Adorno)/En México, por Melchior Ocharte./Anno 1605. 
16 hojs. s. núm. $\dagger 166$ fols. $†$ hoj. s. núm. - sings. $* *^{*}-\dagger-A^{s}-V^{s}$. Libro rarísimo hoy día en la propiedad del erudito señor Conway, ${ }^{18}$ declara estar imprimiendo una Floresta cortesana, esto es, La bella Cotalda y cerco de Paris. Relación de las grandezas del Perú, México $i$ los Angeles.

En consecuencia, debio haberse impreso entre 1600 y 1606 , puesto que además parece lógico que, de haber tenido preparada para las prensas y no publicada ya La bella Cotalda, hubiese hecho mención de ella en la nota aludida.

Parece ser que tuwo alguna circulación, puesto que en manifestaciones presentadas al Tribunal del Santo Oficio en el siglo xvir, Menoria de los libros que manifiesta Simón García Becerril, aparece este libro inventariado. ${ }^{19}$

Sin embargo, no ha llegado completo a mi conocimiento, no se conocen sino unas cuantas fojas, encontradas pegadas entre sí, formando una pasta o cubierta homogénea. E1 hecho no es de extrañar, si se tiene en cuenta que otras preseas de nuestra riquísima bibliografía mexicana fueron halladas en iguales circunstancias, tales por ejemplo: el Diálogo de doctrina cristiana en lengua de Michoacán, de fray Maturino Gilberti, editado en 1559; la Gaceta mexicana del siglo XVII.

Tanto Nicolás León como José Toribio Medina tuvieron, en pastas de libros viejos, valiosos hallazgos bibliográficos.

"La escasez de papel fué también causa de que los encuadernadores tuvieran que echar mano de los pliegos impresos para guardas de los libros y en los primeros tiempos pasta para fabricar cartón de las tapas." 20

Tengo, pues, en mi poder 25 fojas en $16^{\circ}$ que corresponden de la foja 126 a la 135 inclusive; de la 141 a la 147 y con igual numeración, empezando en la foja 135 y terminando en la 142 ; estas últimas no corresponden a las primeras en el texto, lo que hace suponer, o bien que estuviese el libro dividido en dos partes empezando cada una con nueva numeración, o que constara de dos volúmenes. Sea lo que fuere, eso es todo - bien raquítico por cierto-, lo que poseo y se conoce de este libro.

Precisamente por ser tan escasas las fojas no se puede justipreciar en toda su amplitud la obra, que se halla escrita en tercetos endecasilabos, nueve tercetos en cada foja. Alternan con ellos al- 
gunos sonetos, silvas y redondillas. En la foja 129 (vuelta) un soneto dedicado a los Receptores del número; en la 131 una silva, cinco versos de siete sílabas cada uno, dedicada Al Dean y Cabildo desta metropolitana; en la 147 (vuelta) otro soneto $A$ las damas ilvustres mexicanas; en la foja 139 segunda serie, cinco redondillas de ocho sílabas cada verso, dedicadas Al licenciado Gvtierre Bernardo de Quirós. Inquisidor Apostólico destos Reynos, y por último, en la foja 140, otro soneto al Mariscal don Carlos de Arellano y Luna, en diálogo entre la fama y tiempo.

Literariamente considerados estos versos, tienen poco valor. No alcanzan a mover interés, son de trazo pesado, y en ellos se abusa del servilismo. Son versos laudatorios en los que se mencionan receptores y procuradores de número, Cabildo de Catedral, Cabildo de la ciudad y damas de la corte, así como a otros personajes de nota, como los citados Inquisidor y Mariscal de Castilla. No se entreveé el alcance de la obra puesto en el título. Aparte del valor bibliográfico servirá la obra, o mejor dicho esta mínima parte de ella, para corroborar nombres de regidores y algunos personajes de la época, cosa por otra parte que es más fácil en otras fuentes.

\section{Manuel Carrera Stampa}

\section{NOT A S}

1 Miguel Cervantes Saavedra, El Ingenioso Hidago Don Quijote de la Mancha. Edit. Saturnino Calleja, S. A. Madrid, 1905, cap. vI, pp. 41-45.

2 Ibid., pp. 46-47.

3 Miguel Cervantes Saavedra, Viaje al Parnaso. Madrid, Antonio de Sancha, 1784, pp. 71, 108-109.

4 Encomio de los ingenios serillanos, Sevilla, 1623. El título completo es: El pastor de Iberia, compuesto por Bernardo de la Vega, gentil-hombre andaluz, dirigido a D.J. Téllez Girón, duque y conde de Ureña, Camarero Mayor del Rey mestro señor y su Notario Mayor de los Reinos de Castilla (Escudo). Con privilegio en Sevilla, en casa de J. de León, impresor, 1591. A costa de Bernardo de la Vega, en 8, 228 pp.

5 Así lo expresa la licencia que transcribo más adelante.

6 Bartolomé José Gallardo, Ensayo de una biblioteca española de libros raros y curiosos. Madrid, Imp, y fundición de Manuel Tello, 1889. IV, pp. 957$958, N^{\circ} 4201$. 
7 Epitome de la Biblioteca Oriental y Occidental, Náutica Geográfica por el Lic.... Prólogo de Diego Luis Molinari. Edic. Bibliófilos Argentinos. Buenos Aires. Juan Roldán. Tit. XIv, p. 97.

8 Bibliotheca Hispana Nova sive hispanorum scriptorum. Matriti. Joachinum de Ibarra, 1783, I, 228. Dice: Barnardus de la Vega, matritensis canonicus de Tucuman in meridionali America, scriptit versibus: La Bella Cotalda $y$ cerco de Paris, Simulque: Relacion de las grandezas de Piru, Mexico y los Angeles. Mexico. Apud Melchiorem de Ocharte 1601, in 8, eiditus ejusdem credo anctoris est.

9 Biblioteca Hispano Americana Septentrional o Catálogo y noticia de los literatos, etc. Publica José Rafael Enríquez Trespalacios Beristáin, sobrino del autor. México, Alejandro Valdés; 1821 (3 vols.), no lo trae; Bibliografía Mexicana del siglo XVI (1530-1600), $1^{\text {a }}$ parte. México, Librería de Andrade y Morales. Suces. Imp. Francisco Díaz de León, 1886, no lo trae.

10 Ensayo bibliográfico de México del siglo XVII, $2^{3}$ ed. México. Imp. del Museo Nacional, 1894, p. 1, No 1.

11 Biblioteca Hispano-Americana (1493-1810). Santiago de Chile, Impreso y Grabado en casa del autor, 1898, I, 513-514. Manual del librero Hispano Americano. Barcelona, Librería Anticuaria. Londres. Maggs Bros, 1927. T. 7, TGZ, pp. 124 b.

12 José Toribio Medina, La imiprenta en México (1539-1821). Santiago de Chile. Impreso en casa del autor, 1912. II, pp. vII, vIII, cIX.

13 Ibid., II, VII, VIII.

14 Archivo General de la Nación (de aquí en adelante AGN.) Inquisición. Testificaciones contra Bernardo Vega, Canónigo de Tucumán por tener que referirse a la cédula real contra los inquisidores. T. $267, N^{2} 24,32$ fss.

15 AGN. General de Parte, t. 5, p. 190 v. Publicado en "Boletín del Archivo General de la Nación", vII, (1936), "núm. 4, pp. 481-482.

16 Actas de Cabildo de la Ciudad de Mérico, libro de Cabildo que comienza en 8 de octubre de 1599 y termina en 8 de febrero de 1602. México. Imp. de Aguilar e hijos, 1899, t. Xıv, p. 133, acta de 18 de julio de 1600 .

17 Ibid., p. 142, acta de 11 de septiembre de 1600 .

18 Agustín Millares Carlo, Dos notas de bibliografía colonial mexicana, en "Filosofía y Letras. Revista de la Facultad de Filosofía y Letras de la Universidad Nacional de México", iv, (1942), N 7, pp. 95-107.

19 Bibliotecas y librerias coloniales (1585-1694). Introducción de Edmundo O'Gorman, en "Boletín del Archivo General de la Nación”, Ix, (1939), p. $703, \mathrm{~N}^{9} 6$.

20. Medina, op. cit., I, vII-VIII. 
